\title{
Post-Mortem Chemical Changes in Poultry Breast Meat Monitored With Visible-Near Infrared Spectroscopy
}

\author{
Samantha A. Hawkins ${ }^{1}$, Brian Bowker ${ }^{1}$, Hong Zhuang $^{1}$, Gary Gamble ${ }^{1}$ \& Ronald Holser ${ }^{1}$ \\ ${ }^{1}$ Department of Agriculture-Agricultural Research Services, Quality and Safety Assessment Research Unit, \\ Richard B. Russell Research Center, 950 College Station Rd, Athens, GA 30605, United States \\ Correspondence: Samantha A. Hawkins, Department of Agriculture-Agricultural Research Services, Quality and \\ Safety Assessment Research Unit, Richard B. Russell Research Center, 950 College Station Rd, Athens, GA \\ 30605, United States. Tel: 1-706-546-3454. E-mail: samantha.hawkins@ars.usda.gov
}

\author{
Received: December 10, 2013 Accepted: March 23, 2014 Online Published: April 3, 2014 \\ doi:10.5539/jfr.v3n3p57 \\ URL: http://dx.doi.org/10.5539/jfr.v3n3p57
}

\begin{abstract}
Chicken meat undergoes significant chemical and structural changes with postmortem time that influence meat quality characteristics. The objective of this study was to measure the visible-near infrared (vis-NIR) spectral differences in broiler breast fillets at $0.5,4,24$, and $120 \mathrm{~h}$ postmortem. Muscle samples were flash frozen and freeze-dried prior to spectra analysis. In the visible region of the spectra $(400-700 \mathrm{~nm})$ changes in myoglobin protein peaks were observed with postmortem time. Freeze-drying muscle samples provided additional information from the NIR region of the spectra $(800-2500 \mathrm{~nm})$ on muscle protein changes during postmortem aging. Alterations to the $\beta$-sheet and $\alpha$-helix structures of myofibrillar proteins and changes in the amount of bound water were observed in the NIR region with postmortem aging. Data from this study demonstrate that changes in breast fillets with postmortem time that are related to meat quality traits are detectable using vis-NIR spectroscopy.
\end{abstract}

Keywords: vis-NIR spectroscopy, chicken, freeze-dried, postmortem aging, breast muscle

\section{Introduction}

Meat quality traits such as color, texture, flavor, and water-holding capacity contribute to consumer acceptance of fresh poultry products. Final meat quality traits are often difficult to predict early postmortem and there is a need to develop quick, non-invasive measurement techniques for fresh meat products that can be implemented online in a processing plant. Visible - Near Infrared (vis-NIR) spectroscopy has been used extensively in the agricultural community to measure water, protein, and fat concentrations in food products, especially as they pertain to food quality (Liu, Lyon, Windham, Lyon, \& Savage, 2004a, 2004b; Lyon, Windham, Lyon, \& Barton, 2001; Mlcek, Rop, Sustova, Simeonovova, \& Gal, 2010; Prieto, Roehe, Lavin, Batten, \& Andres, 2009; Windham, Lawrence, \& Feldner, 2003; Yang, Meng, Ren, Zhou, \& Xie, 2010). Vis-NIR spectroscopy has significant potential in the poultry industry for measurement of meat quality traits because it is rapid, can be used non-destructively, and can give accurate measurements. It has been studied for its use in prediction of fat content, water holding capacity, color, and texture in beef, pork, and poultry products with mixed results ${ }^{7}$.

With time postmortem, numerous biochemical and ultrastructural changes progressively occur within the tissue during the transformation of muscle to meat that impact final product quality characteristics. Despite the dynamic nature of postmortem muscle, studies attempting to predict chicken meat quality traits using vis-NIR spectroscopy have typically focused on measuring the spectra at a single postmortem time (Berzaghi, Dalla Zotte, Jansson, \& Andrighetto, 2005; Liu et al., 2004a; Meullenet, Jonville, Grezes, \& Owens, 2004; Samuel, Park, Sohn, \& Wicker, 2011; Windham, et al., 2003). One previous report used vis-NIR spectroscopy to study the protein changes in chicken breast fillets at multiple time points from 2 to 18 days postmortem (Liu \& Chen, 2000). This study, however, was only able to draw useful information from the visible region of the spectra due to the strong presence of water bands in the NIR region.

It is unknown if the effectiveness of using vis-NIR spectroscopy to predict chicken meat quality is influenced by the postmortem time of spectra measurement, particularly during the time period which is most crucial in meat quality development $(<24 \mathrm{~h}$ postmortem). In order to determine the role that postmortem time plays in measuring meat quality with vis-NIR, the initial step is to test the hypothesis that the vis-NIR spectra of raw 
chicken meat fluctuate depending upon postmortem time of measurement. Thus, the primary objective of this study was to measure the vis-NIR spectra of normal quality broiler breast fillets at $0.5,4,24$, and $120 \mathrm{~h}$ postmortem in order to observe the effect of postmortem time on various characteristics of the spectra. To minimize carcass to carcass variation in the vis-NIR spectra measurements each broiler carcass used in this study was sampled at each of the four postmortem time points.

Postmortem changes in protein denaturation and degradation play a key role in determining final meat quality. In using vis-NIR with fresh meat products, however, studying specific protein structures and less obvious chemical changes that play key roles in determining meat quality traits can be difficult due to the significant and overriding contribution of water to the spectra. Its use in fresh meat products has limited the chemical identification to 'crude proteins in the NIR region' which is limiting in the identification of specific protein changes contributing to the quality parameters. Additionally, some have even reported high errors in the prediction of crude protein and fat content in muscle foods (Cozzolino \& Murray, 2002; McDevitt, Gavin, Andres, \& Murray, 2005; Prieto et al., 2009; Samuel et al., 2011). Some of the error may be due to the fact that water bands obscure or overlap these other peaks rendering the area under the peak useless as a predictor of chemical concentrations. In order to better assess the impact that postmortem time has on the NIR region of the spectra, breast fillet samples in this study were freeze-dried prior to spectral analysis to reduce the influence of water. This provided a means to further our understanding of postmortem chemical changes and how they apply to muscle foods and the potential for using vis-NIR technologies for measuring poultry meat quality.

\section{Materials and Methods}

\subsection{Sample Collection and Preparation}

Thirty-six broiler carcasses were collected from a local poultry processing plant on two different days, eighteen carcasses per day. The carcasses were randomly chosen from the processing line following evisceration but prior to carcass chilling. Left and right breast fillets (Pectoralis major muscle) from each carcass were removed. The cranial and caudal portions of one fillet from each carcass were randomly assigned sampling times of 0.5 and $4 \mathrm{~h}$ postmortem, while the other fillet was similarly assigned sampling times of 24 and $120 \mathrm{~h}$ postmortem. Fillets were chilled in individual plastic bags in an ice bath from 0.5 to $2 \mathrm{~h}$ postmortem followed by refrigerated storage at $4{ }^{\circ} \mathrm{C}$. At $4 \mathrm{~h}$ postmortem, the temperatures of the intact fillets were measured. At $24 \mathrm{~h}$ postmortem, the fillet portion designated for $120 \mathrm{~h}$ sampling was vacuum packaged for refrigerated storage. At designated sampling times, the muscle samples were removed from the fillets and quickly knife minced into small pieces $(0.5 \times 0.5 \times$ $0.5 \mathrm{~cm})$. Samples were then flash frozen in liquid nitrogen and stored at $-80{ }^{\circ} \mathrm{C}$. A portion of each frozen muscle samples was then freeze-dried using a Virtis Freezemobile 25 EL system (SP Scientific, Warminster, PA). All samples were dried for the same length of time to a total residual water content of less than $10 \%$, as determined by water content measurements (AOAC, 1990). Prior to collection of the vis-NIR spectra freeze-dried samples were ground into a powder using a coffee grinder. Three samples had to be discarded due to contamination.

\subsection{Meat Quality Measurements}

To ensure that vis-NIR spectra were collected from broiler breast fillets of normal meat quality, 24 hour postmortem measurements of color, $\mathrm{pH}$, and water-holding capacity were made on one fillet from each broiler carcass. At $24 \mathrm{~h}$ postmortem, color measurements were made on the medial surface of the bone side of the intact raw fillets with a Minolta Spectrophotometer CM-700d (Konica Minolta Inc., Ramsey, NJ). Measurements were recorded as the average of three readings and expressed in terms of CIE values for lightness ( $\left.\mathrm{L}^{*}\right)$, redness $\left(\mathrm{a}^{*}\right)$, and yellowness $\left(\mathrm{b}^{*}\right)$. A portion of the frozen, non-freeze-dried sample taken at $24 \mathrm{~h}$ postmortem was utilized for pH measurements using an Orion pH electrode (model 8220 BNWP) and meter (model 330, Orion Research Inc., Beverly, MA) and for determining water-holding capacity measurements using salt-induced water uptake and cooking yield assays (Stewart, Fletcher, Hamm, \& Thomson, 1984; Zhuang \& Savage, 2012).

\subsection{Spectroscopy}

The room temperature, powdered fillet samples were loaded into quartz window sample cells. These were analyzed using diffuse reflectance visible-near infrared spectroscopy on a Foss XDS spectrometer (Foss, Denmark). Each spectrum was collected using 32 scans over the 400 to $2500 \mathrm{~nm}$ range at $2 \mathrm{~nm}$ intervals and the data was recorded as $\log 1 /$ Reflectance (normally reported on graphs as simply $1 / \mathrm{R}$ ). The data were analyzed using The Unscrambler X software (Camo Software, Norway). The Unscrambler was used to find patterns, trends and perform calculations, such as derivatives on the spectra in order to identify the peaks of interest in the data. The first derivative, using Savitsky-Golay filter and 5 point smoothing, was also normalized to the peak at $1190 \mathrm{~nm}$ prior to analysis. 


\section{Results and Discussion}

In order to determine the effects of postmortem time of measurement on the characteristics of the vis-NIR spectra of breast fillets, four sampling times were chosen that were expected to yield breast muscle samples that varied in their biochemical composition and muscle ultrastructure due to the inherent progression of postmortem changes. Sampling time points $(0.5,4,24$, and $120 \mathrm{~h})$ were selected to correspond with specific postmortem events in the tissue that are known to impact fresh meat quality in broiler breast fillets. At the earliest sampling time $(0.5 \mathrm{~h})$, the $\mathrm{pH}$ and temperature of the tissue were still rapidly declining and the samples were considered pre-rigor. By $4 \mathrm{~h}$ postmortem, glycolysis and $\mathrm{pH}$ decline within the tissue would have been virtually complete, rigor mortis would have set in, but aging-related proteolysis would have been minimal. At $24 \mathrm{~h}$ postmortem, degradation of myofibrillar and cytoskeletal proteins by endogenous enzyme systems would be evident but the tissue would not yet have lost an appreciable amount of moisture. By $120 \mathrm{~h}$ postmortem, aging tenderization would have been completed and the fillets would have lost significant amounts of extracellular fluid as exudate.

Basic measures of final meat quality ( $24 \mathrm{~h}$ postmortem) were utilized in this study to verify that breast fillets underwent typical postmortem changes and were of normal quality (Table 1). While the $\mathrm{pH}$ was slightly lower than expected, color and WHC measurements at $24 \mathrm{~h}$ postmortem and the fillet temperature at $4 \mathrm{~h}$ postmortem were indicative of normal quality fillets and suggested that the breast fillets utilized in this study underwent typical postmortem changes.

Table 1 . Meat quality characteristics at $24 \mathrm{~h}$ postmortem and meat temperature at $4 \mathrm{~h}$ postmortem in broiler breast fillets $(\mathrm{mean} \pm \mathrm{SD})$

\begin{tabular}{llllllll}
\hline & & \multicolumn{3}{l}{ Color Measurements } & \multicolumn{3}{l}{ WHC Measurements } \\
\cline { 3 - 7 } & $\mathrm{pH}_{24 \mathrm{~h}}$ & $\mathrm{~L}^{*}$ & $\mathrm{a}^{*}$ & $\mathrm{~b}^{*}$ & $\mathrm{SIWG}(\%)^{1}$ & $\mathrm{CY}(\%)^{2}$ & $\begin{array}{l}\text { Temp. } \\
\left({ }^{\circ} \mathrm{C}\right)\end{array}$ \\
\hline $\begin{array}{l}\text { Fillets } \\
(\mathrm{n}=36)\end{array}$ & $5.66 \pm 0.14$ & $57.6 \pm 4.7$ & $-0.7 \pm 1.1$ & $12.5 \pm 1.2$ & $24.8 \pm 8.3$ & $74.4 \pm 5.4$ & $1.5 \pm 0.8$ \\
\hline
\end{tabular}

${ }^{1}$ SIWG (salt-induced water gain).

${ }^{2} \mathrm{CY}$ (cooking yield).

Previous work has demonstrated how difficult it is to observe details other than water, crude protein, and fat content present in fresh chicken meat using vis-NIR spectroscopy (Liu \& Chen, 2000; Lyon et al., 2001; Windham et al., 2003). As a result, this research was conducted on samples that were freeze-dried prior to vis-NIR analysis in order to observe those combination and overtone vibrational bands that normally are obscured by water bands. While freeze-drying is not a solution that can be logistically implemented on-line during processing, it serves as a research model and provides for a better interpretation of the chemical changes occurring in the breast fillets in the immediate postmortem timeframe.

A spectrum taken of fresh chicken breast muscle is shown in Figure 1a in comparison to a freeze-dried sample shown in Figure 1b. The spectrum of the fresh sample shown was collected approximately 4 hours postmortem and the freeze-dried sample was flash frozen at the same time. The most notable differences were in the NIR region of the spectrum $(800-2500 \mathrm{~nm})$ because of the near absence of water in the freeze-dried samples. The peaks in the visible range $(400-800 \mathrm{~nm}$ ) were attributed to the sarcoplasmic protein (myoglobin) primarily responsible for variations in meat color. The intensities of these peaks were higher in the fresh samples, but the same peaks were distinguished in both fresh and freeze-dried samples. Many more peaks were observed in the NIR spectra of the freeze-dried samples suggesting that removing water prior to spectral analysis yields additional chemical information on muscle constituents that potentially play a large role in determining meat quality. 

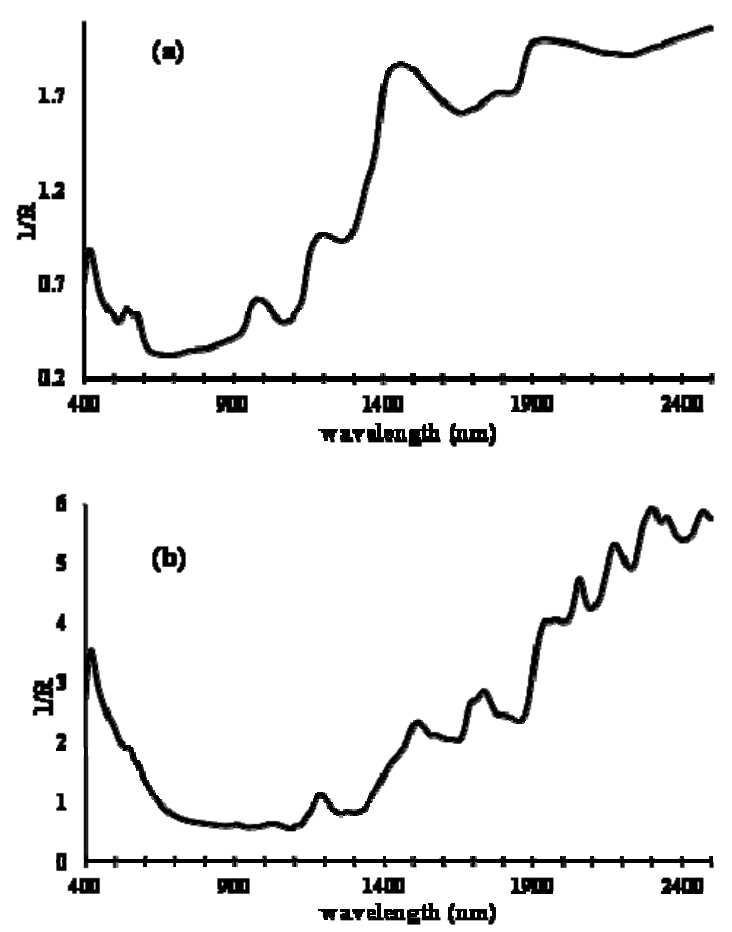

Figure 1. Visible-Near Infrared Spectra of Poultry fillet samples

Visible-Near Infrared spectra of a) raw chicken breast muscle 4 hours post mortem and b) freeze dried chicken breast muscle that was flash frozen at 4 hours postmortem.

The broiler carcasses were acquired on two different processing days and from separate flocks. A principal component analysis (PCA) score plot of all 141 samples revealed that the fillet samples could be segregated by processing day, whereas the PCA score plot of each processing day individually segregated samples by postmortem time. This was true even after taking the derivative and normalizing the spectra. The score plot of all samples and of those from the second processing day are shown in Figure 2 ( $a$ and b, respectively). The spectra demonstrated a processing day/flock effect due to the two sets exhibiting different peak intensities. Regardless of processing day or flock, however, similar trends were observed in the spectra with respect to the chemical changes that occurred over the four postmortem sampling times. Similarly, spectral differences due to processing day and flock have been observed in previous experiments on fresh chicken fillets. Due to this effect, the figures henceforth show spectra from only one processing day for clarity. However, the trends in the peak effects due to postmortem aging were consistent in the fillet samples from the different processing days, unless otherwise noted. 

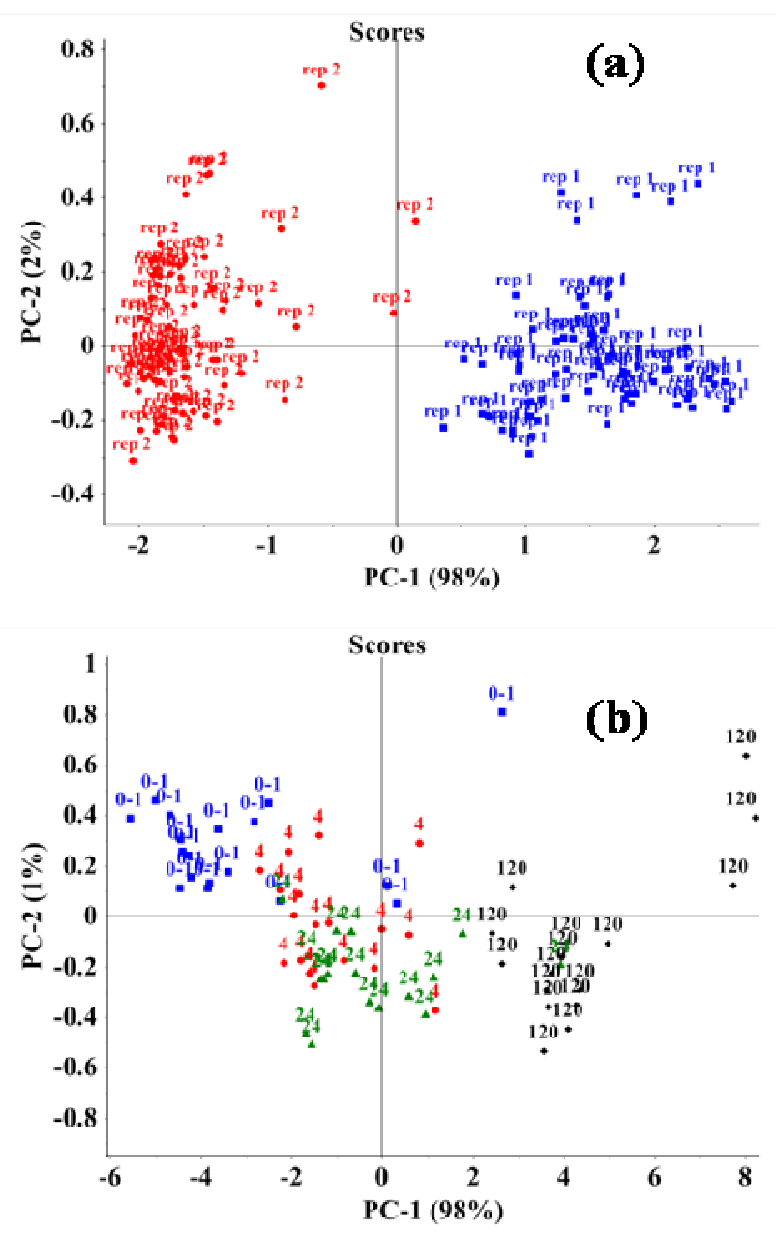

Figure 2. Score plots

Principal component analysis was performed across the 400-2500 nm region to determine if any specific chemical changes can be detected over a range of post-mortem times. The score charts demonstrate a) the day/flock effect and b) within one day/flock set peak changes are distinguishable in the spectra indicating observable chemical changes.

Figure 3 shows average spectra of the four different postmortem time points in the visible region after taking the (Savitzky Golay) first derivative and normalizing at $1190 \mathrm{~nm}$. The changes in the spectra are easier to observe in the plot of the derivative. In Figure 3, the region of the first derivative near $430 \mathrm{~nm}$ is attributed to deoxymyoglobin, the region around $485 \mathrm{~nm}$ to metmyoglobin, and the region around $545 \mathrm{~nm}$ to oxymyoglobin (Liu, Chen, \& Ozaki, 2000). The oxidation state of the iron within the heme ring of myoglobin determines the pigment's influence on fresh meat color. In its reduced forms, deoxymyoglobin is purplish and oxymyoglobin is bright red in appearance. Metmyoglobin is a brown color and occurs when the heme portion of the pigment is in the oxidized state(Aberle, 2001). 


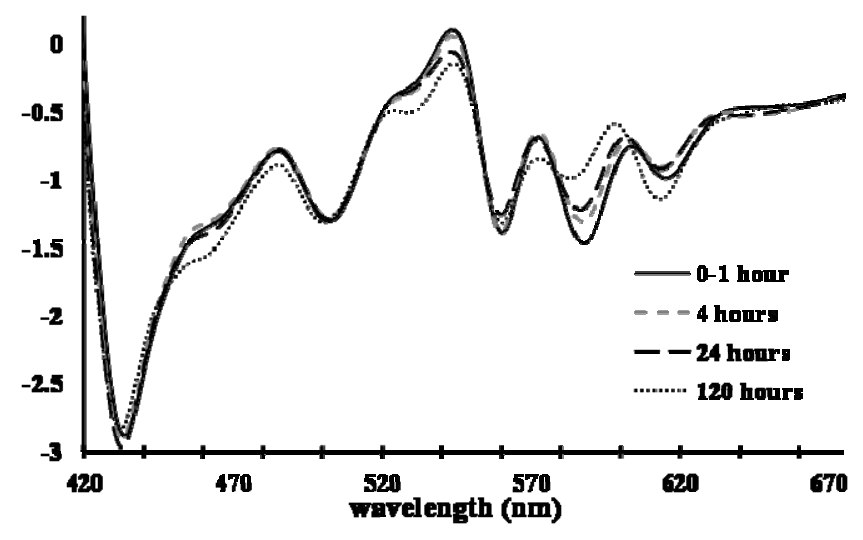

Figure 3. Freeze dried samples

Spectra from a set of freeze-dried samples over the four time periods in the 400-670 nm range. The spectra are the averages of all samples for a given time period and the Savitzky-Golay first derivative with 5 point smoothing algorithm was applied.

Data from this study suggest that vis-NIR spectroscopy is capable of detecting postmortem changes in the myoglobin molecule that influence breast fillet color. For the peaks due to deoxymyoglobin and metmyoglobin (Figure 3), the general positions and relative peak intensity ratios are fairly consistent between samples at $0.5,4$, and $24 \mathrm{~h}$ postmortem time. The metmyoglobin peak, however, showed significant changes in intensity between 24 and $120 \mathrm{~h}$ postmortem. The oxymyoglobin peak exhibited progressive changes in intensity throughout the entire postmortem time period $(0.5$ to $120 \mathrm{~h})$ in this study. Other peaks near the oxymyoglobin and metmyoglobin peaks are postulated to be due to changes in the secondary structure of the proteins. Previously, with aging of chicken meat from 2 to 9 days postmortem, changes were observed in all three regions, with the intensity of metmyoglobin increasing and the intensity of oxymyoglobin decreasing (Liu \& Chen, 2000). The observations of the current study were that all three types of myoglobin decreased in intensity over the first 120 hours postmortem. This loss of intensity may have been related to the fact that myoglobin content of the muscle likely decreased with postmortem storage as the sarcoplasmic protein fraction of the muscle was progressively lost as muscle exudate. Furthermore, changes in the ratios of these proteins may have been due to interconversion or even degradation as a result of postmortem storage.

Averages from the NIR region of the spectrum over the four postmortem time points are shown for the fillet samples in Figures 4 and 5, raw data and first derivative respectively. The protein peaks observed in this region were mostly due to the myofibrillar proteins. It is unlikely that stromal proteins contributed much to these peaks due to the low abundance of connective tissue in the breast muscles of broilers at market age ( $\sim 6$ weeks old). Myofibrillar proteins, particularly myosin, are predominantly responsible for the water-holding capacity of meat through both direct protein-water interactions and the entrapment of water within the myofilaments lattice of the myofibrils. Again, the spectral changes were more clearly demonstrated by looking at the first derivative. The following assignments were made to the peaks in the non-processed spectra. Absorption bands of the third overtone and second overtone of C-H stretching modes are present at 908 and $1190 \mathrm{~nm}$, respectively. First overtone $\mathrm{O}-\mathrm{H} / \mathrm{N}-\mathrm{H}$ stretching modes of water bonded amide groups in meat proteins are present at 1460 and $1512 \mathrm{~nm}$. The peak at $1690 \mathrm{~nm}$ is an amide of peptide $\beta$ sheet structures of proteins. The peak at $1740 \mathrm{~nm}$ is assigned to the carbonyl amine hydrogen bond peptide link of $\alpha$ helix structure of proteins. The peak at $1940 \mathrm{~nm}$ is from residual water. The peak at $1980 \mathrm{~nm}$ can be assigned to the asymmetric stretch and in plane bend combination of $\mathrm{N}-\mathrm{H}$. The peak at $2056 \mathrm{~nm}$ is an amide I combination of $\mathrm{N}-\mathrm{H}$ stretching and $\mathrm{C}=\mathrm{O}$ stretching. The peak at $2178 \mathrm{~nm}$ is the second overtone of N-H bending in proteins. The peak at $2300 \mathrm{~nm}$ is assigned to the second overtone of $\mathrm{C}-\mathrm{H}$ bending in amide functional groups. Combination bands from lipids are present at 2350 $\mathrm{nm}$ and $2470 \mathrm{~nm}$ (Workman Jr., 2008). Due to the exudation that occurred during the aging of the breast samples and the freeze-drying process, most of the free and immobilized water within the tissue was removed and the remaining peaks corresponding to water likely represent only the bound water that is located within the protein molecules. 


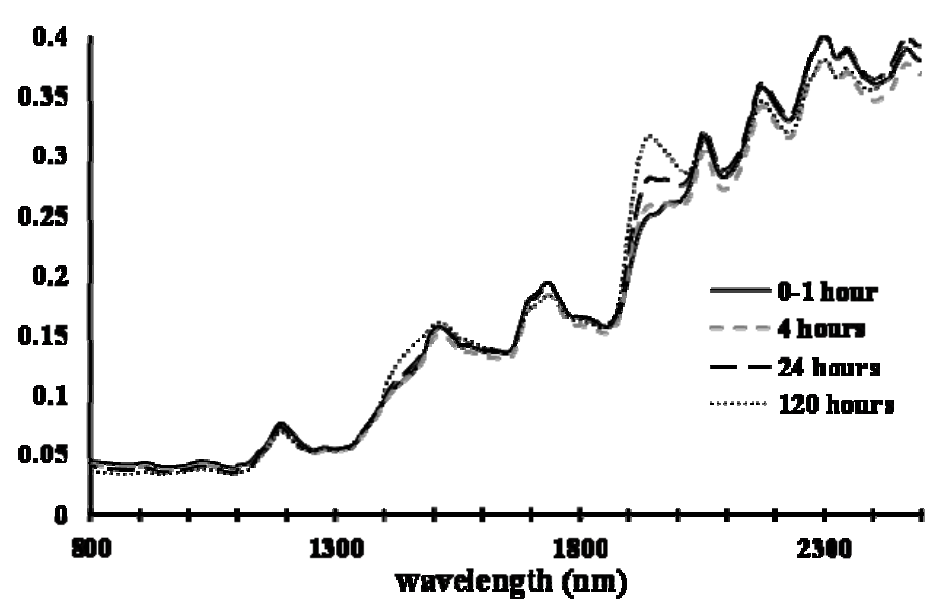

Figure 4. Spectra from a set of freeze-dried samples over the four time periods in the $800-2500 \mathrm{~nm}$ range. The spectra are the averages of all samples for a given time period

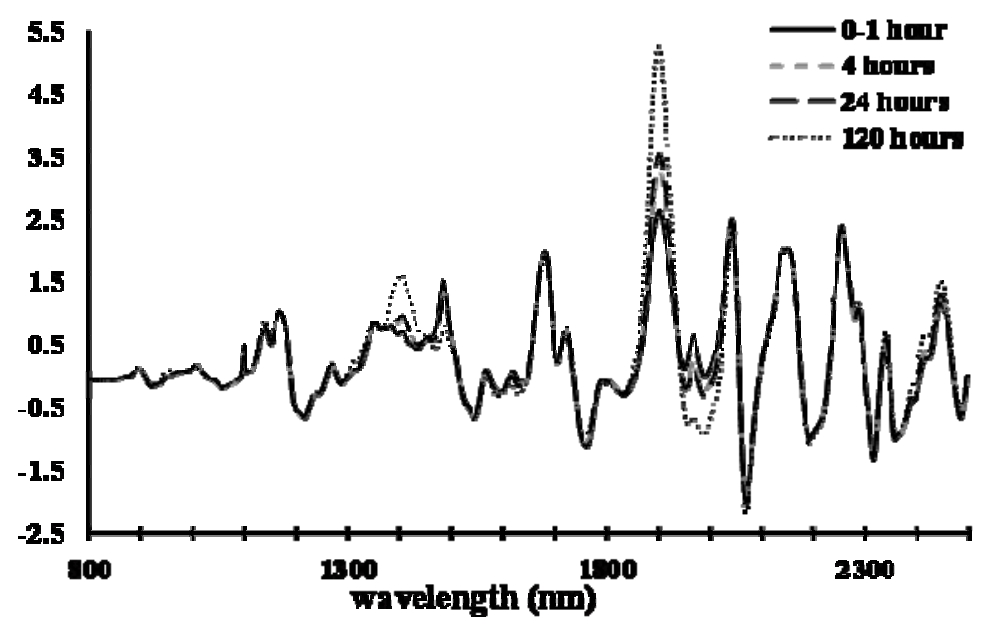

Figure 5. The same spectra from Figure 4, with the Savitzky-Golay first derivative with 5 point smoothing algorithm applied

By analyzing the first derivative spectra, it was evident that the most significant changes that occurred during the time from immediate postmortem to $120 \mathrm{~h}$ postmortem were in the $1360-1515 \mathrm{~nm}$ and $1850-2025 \mathrm{~nm}$ ranges. In both regions there was a significant change between 0.5 and $4 \mathrm{~h}$, little change between 4 and $24 \mathrm{~h}$ and then a significant change between 24 and $120 \mathrm{~h}$ postmortem. The peaks in both ranges were likely due to hydrogen bonding between residual water and N-H of amide groups in the proteins. The trend was observed in all fillet samples demonstrating that there was more bound water with longer postmortem times. There was a slight change in the $\beta$ sheet structure and $\alpha$ helix structure during the short time postmortem, observed in the region $1660-1775 \mathrm{~nm}$. Overall, the $\beta$ sheet and $\alpha$ helix structural peaks and the bound water peaks in the NIR range exhibited changes between the first two time points, little change between 4 and $24 \mathrm{~h}$ and then substantial changes up to the $120 \mathrm{~h}$ postmortem. It is likely then that during the conformation change the proteins are breaking internal hydrogen bonds and holding more strongly bound water in the meat. The other protein peaks in the NIR region show little change between $0.5 \mathrm{~h}$ postmortem and 24 hours postmortem. The ability to observe the changes in the concentrations of the protein structures and their relationship to increased amounts of bound water help further understanding of how aging meat influences water holding capacity. The observation that 
aging the fillets increases the abundance of bound water supports the idea that postmortem proteolysis contributes to the improvements in water-holding capacity observed in meat with aging (Kristensen \& Purslow, 2001). It is argued that the degradation of cytoskeletal proteins removes linkages between myofibrils, thus with lateral shrinkage of the myofibrils during rigor there is less water expelled into the extracellular spaces and out of the muscle as drip or exudates (Huff-Lonergan \& Lonergan, 2005). The findings in this study suggest that improved water-holding capacity with postmortem aging could also be due directly to the increased availability of water-binding sites on muscle proteins due to postmortem proteolysis.

The findings in this study support the hypothesis that the vis-NIR spectra of broiler breast fillets vary with postmortem time. Data indicate that important structural and chemical changes in the muscle with postmortem aging can be detected by vis-NIR spectroscopy. Further, research is needed, however, to link spectral differences with the precise mechanisms controlling meat quality development and to determine if there is an optimal postmortem time for utilizing vis-NIR spectra to predict meat quality properties in broiler breast fillets.

\section{Acknowledgements}

The authors would like to express their appreciation to Elizabeth Barton and Candace Betts for their dedication and contributions to this work.

\section{Supporting Information}

The use of trade, firm, or corporation names in this publication is for the information and convenience of the reader. Such use does not constitute an official endorsement or approval by the United States Department of Agriculture or the Agricultural Research Service of any product or service to the exclusion of others that may be suitable.

\section{References}

Aberle, E. D., Forrest, J. C., Gerrard, D. E., \& Mills, E. W. (2001). Principles of Meat Science (4th ed.). Dubuque, IA: Kendall/Hunt Publishing Co.

AOAC. (1990). Official Method of Analysis. Washington, D.C.

Berzaghi, P., Dalla, Z. A., Jansson, L. M., \& Andrighetto, I. (2005). Near-infrared reflectance spectroscopy as a method to predict chemical composition of breast meat and discriminate between different n-3 feeding sources. Poultry Science, 84(1), 128-136. http://dx.doi.org/10.1093/ps/84.1.128

Cozzolino, D., \& Murray, I. (2002). Effect of sample presentation and animal muscle species on the analysis of meat by near infrared reflectance spectroscopy. Journal of near Infrared Spectroscopy, 10(1), 37-44. http://dx.doi.org/10.1255/jnirs.347

Huff-Lonergan, E., \& Lonergan, S. M. (2005). Mechanisms of water-holding capacity of meat: The role of postmortem biochemical and structural changes. Meat Science, 71(1), 194-204. http://dx.doi.org/10.1016/j.meatsci.2005.04.022

Kristensen, L., \& Purslow, P. P. (2001). The effect of ageing on the water-holding capacity of pork: role of cytoskeletal proteins. Meat Science, 58(1), 17-23. http://dx.doi.org/10.1016/S0309-1740(00)00125-X

Liu, Y. L., \& Chen, Y. R. (2000). Two-dimensional correlation spectroscopy study of visible and near-infrared spectral variations of chicken meats in cold storage. Applied Spectroscopy, 54(10), 1458-1470. http://dx.doi.org/10.1366/0003702001948600

Liu, Y. L., Chen, Y. R., \& Ozaki, Y. (2000). Characterization of visible spectral intensity variations of wholesome and unwholesome chicken meats with two-dimensional correlation spectroscopy. Applied Spectroscopy, 54(4), 587-594. http://dx.doi.org/10.1366/0003702001949780

Liu, Y., Lyon, B. G., Windham, W. R., Lyon, C. E., \& Savage, E. M. (2004a). Prediction of physical, color, and sensory characteristics of broiler breasts by visible/near infrared reflectance spectroscopy. Poultry Science, 83(8), 1467-1474. http://dx.doi.org/10.1093/ps/83.8.1467

Liu, Y., Lyon, B. G., Windham, W. R., Lyon, C. E., \& Savage, E. M. (2004b). Principal component analysis of physical, color, and sensory characteristics of chicken breasts deboned at two, four, six, and twenty-four hours postmortem. Poultry Science, 83(1), 101-108. http://dx.doi.org/10.1093/ps/83.1.101

Lyon, B. G., Windham, W. R., Lyon, C. E., \& Barton, F. E. (2001). Sensory characteristics and near-infrared spectroscopy of broiler breast meat from various chill-storage regimes. Journal of Food Quality, 24(5), 435-452. http://dx.doi.org/10.1111/j.1745-4557.2001.tb00621.x 
McDevitt, R. M., Gavin, A. J., Andres, S., \& Murray, I. (2005). The ability of visible and near infrared reflectance spectroscopy to predict the chemical composition of ground chicken carcasses and to discriminate between carcasses from different genotypes. Journal of near Infrared Spectroscopy, 13(3), 109-117. http://dx.doi.org/10.1255/jnirs.463

Meullenet, J. F., Jonville, E., Grezes, D., \& Owens, C. M. (2004). Prediction of the texture of cooked poultry pectoralis major muscles by near-infrared reflectance analysis of raw meat. Journal of Texture Studies, 35(6), 573-585. http://dx.doi.org/10.1111/j.1538-7836.2004.01165.x-i1

Mlcek, J., Rop, O., Sustova, K., Simeonovova, J., \& Gal, R. (2010). Potentials of NIR Spectroscopy in Meat Industry. Chemicke Listy, 104(9), 855-860.

Prieto, N., Roehe, R., Lavin, P., Batten, G., \& Andres, S. (2009). Application of near infrared reflectance spectroscopy to predict meat and meat products quality: A review. Meat Science, 83(2), 175-186. http://dx.doi.org/10.1016/j.meatsci.2009.04.016

Samuel, D., Park, B., Sohn, M., \& Wicker, L. (2011). Visible-near-infrared spectroscopy to predict water-holding capacity in normal and pale broiler breast meat. Poultry Science, 90(4), 914-921. http://dx.doi.org/10.3382/ps.2010-01116

Stewart, M. K., Fletcher, D. L., Hamm, D., \& Thomson, J. E. (1984). THE EFFECT OF HOT BONING BROILER BREAST MEAT MUSCLE ON POSTMORTEM PH DECLINE. Poultry Science, 63(11), 2181-2186. http://dx.doi.org/10.3382/ps.0632181

Windham, W. R., Lawrence, K. C., \& Feldner, P. W. (2003). Prediction of fat content in poultry meat by near-infrared transmission analysis. Journal of Applied Poultry Research, 12(1), 69-73. http://dx.doi.org/10.1093/japr/12.1.69

Workman Jr., J., \& Weyer, L. (2008). Practical Guide to Interpretive Near Infrared Spectroscopy. Boca Raton, FL: CRC Press.

Yang, J. S., Meng, Q. X., Ren, L. P., Zhou, Z. M., \& Xie, X. X. (2010). Rapid Evaluation of Beef Quality by NIRS Technology. Spectroscopy and Spectral Analysis, 30(3), 685-687.

Zhuang, H., \& Savage, E. M. (2012). Postmortem aging and freezing and thawing storage enhance ability of early deboned chicken pectoralis major muscle to hold added salt water. Poultry Science, 91(5), 1203-1209. http://dx.doi.org/10.3382/ps.2011-01819

\section{Copyrights}

Copyright for this article is retained by the author(s), with first publication rights granted to the journal.

This is an open-access article distributed under the terms and conditions of the Creative Commons Attribution license (http://creativecommons.org/licenses/by/3.0/). 